Erratum

\title{
Chromosome 17 abnormalities and mutation of the TP53 gene: Correlation between cytogenetics, flow cytometry and molecular analysis in three cases of chronic myeloid leukemia
}

Luize Otero ${ }^{1}$, Geraldo Barroso Cavalcanti Júnior ${ }^{2,3}$, Claudete Esteves Klumb ${ }^{2}$, Marcos Antonio Mauricio Scheiner $^{2}$, Eliane Pereira Simões Magluta ${ }^{2}$, Teresa de Souza Fernandez ${ }^{1,4}$, Maria Luiza Macedo Silva ${ }^{1}$, Virgínia Pires ${ }^{1}$, Gabriela Vasconcelos Andrade ${ }^{1}$, Raquel Ciuvalschi Maia ${ }^{2}$ and Daniel Tabak ${ }^{1}$

${ }^{1}$ Instituto Nacional de Câncer, Centro de Transplante de Medula Óssea, Rio de Janeiro, RJ, Brazil.

${ }^{2}$ Instituto Nacional de Câncer, Serviço de Hematologia, Laboratório de Hematologia Celular e Molecular, Rio de Janeiro, RJ, Brazil.

${ }^{3}$ Universidade Federal do Rio Grande do Norte, Departamento de Análises Clínicas e Toxicológicas, Natal, RN, Brazil.

${ }^{4}$ Universidade do Estado do Rio de Janeiro, Departamento de Patologia Geral, Rio de Janeiro, RJ, Brazil.

Due to a printing error, the image shown in Figure 1 of the article "Chromosome 17 abnormalities and mutation of the TP53 gene: Correlation between cytogenetics, flow cytometry and molecular analysis in three cases of chronic myeloid leukemia" published in v. 28, n. 1, p. 40-43 (2005) was inverted. Please find below the correctly printed Figure.

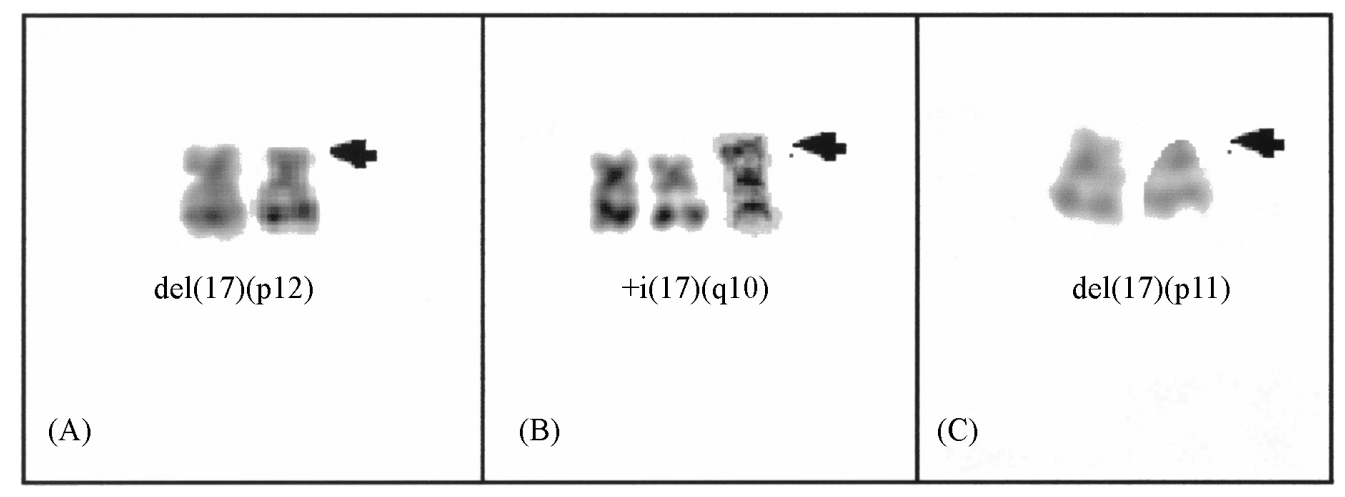

Figure 1 - Partial karyotypes of cases 1 (A), 2 (B) and 3 (C). 